Research Article

\title{
Concentrations, Spatial Distributions, and Sources of Heavy Metals in Surface Soils of the Coal Mining City Wuhai, China
}

\author{
Qingwei Bu $\mathbb{D}^{1},{ }^{1}$ Qingshan Li $\mathbb{D},{ }^{1}$ Handan Zhang $\mathbb{D}^{1},{ }^{1}$ Hongmei Cao $\mathbb{D D}^{1}{ }^{1}$ Wenwen Gong $\left(\mathbb{D},{ }^{2}\right.$ \\ Xin Zhang $\mathbb{D}^{1}{ }^{1}$ Ke Ling $\mathbb{D}^{1},{ }^{1}$ and Yibo Cao ${ }^{1}$ \\ ${ }^{1}$ School of Chemical \& Environmental Engineering, China University of Mining \& Technology-Beijing, Beijing 100083, China \\ ${ }^{2}$ Beijing Research Center for Agricultural Standards and Testing, Beijing Academy of Agriculture and Forestry Science, \\ Beijing 100097, China
}

Correspondence should be addressed to Qingwei Bu; qingwei.bu@cumtb.edu.cn

Received 29 April 2020; Accepted 27 June 2020; Published 22 July 2020

Academic Editor: Luqman C. Abdullah

Copyright (C) 2020 Qingwei Bu et al. This is an open access article distributed under the Creative Commons Attribution License, which permits unrestricted use, distribution, and reproduction in any medium, provided the original work is properly cited.

Various studies have shown that soils surrounding mining areas are seriously polluted by heavy metals. In this study, 58 topsoil samples were systematically collected throughout the coal mining city Wuhai, located within the Inner Mongolia Autonomous Region of China. The concentrations of $\mathrm{As}, \mathrm{Hg}, \mathrm{Cr}, \mathrm{Ni}, \mathrm{Cu}, \mathrm{Zn}, \mathrm{Cd}$, and $\mathrm{Pb}$ in these samples were measured and statistically analyzed. The mean concentrations of all heavy metals were lower than their Grade I values defined by the Chinese Soil Quality Standard. However, the mean concentrations of individual heavy metals in many samples exceeded their background values. The spatial distribution of heavy metals was analyzed by the ordinary kriging interpolation method. The positive matrix factorization model was used to ascertain contamination sources of the eight heavy metals and to apportion the contribution of each source. The most severely polluted area was the Wuhushan mine site in the Wuda district of Wuhai. Our results showed that coal mining strongly affected heavy metal contamination of the local soils. Results of source apportionment indicated that contributions from industrial activities, atmospheric deposition, agricultural activities, and natural sources were $31.3 \%, 26.3 \%, 21.9 \%$, and $20.5 \%$, respectively. This clearly demonstrates that anthropogenic activities have markedly higher contribution rates than natural sources to heavy metal pollution in soils in this area.

\section{Introduction}

Heavy metal contamination has attracted increasing concern over the past decades because it represents a potential hazard to human health and to the environment [1-3]. In particular, heavy metal pollution in soils has become a serious environmental problem around the world, linked to rapid urbanization and industrialization [4, 5]. Heavy metals in soils are completely undegradable and are easily accumulated in organisms through the food chain [6, 7]. In addition, they can be transported to distant downwind areas through atmospheric diffusion and to rivers through surface runoff under rainfall condition [8]. Therefore, soil pollution by heavy metals has become a serious threat to human health and regional ecological systems.

It is commonly recognized that natural and anthropogenic activities are the two major origins of heavy metals.
Natural sources are mainly related to trace elements in the crust [9], while anthropogenic sources are mainly related to metal smelting, fuel and coal combustion, coal mining, and agricultural fertilization $[10,11]$. To identify sources and understand the spatial variation of heavy metals in soils, multivariate statistics combined with geostatistical methods were generally used [12-14]. Typically, geostatistical methods are applied to study the spatial distribution characteristics of heavy metals in soils. The ordinary kriging method is the main interpolation method frequently used to study the spatial distribution characteristics of heavy metals in soils $[12,15]$; it is based on measured data and a semivariogram model to predict unknown sites $[12,15,16]$. The US Environmental Protection Agency's positive matrix factorization (EPA's PMF) model is widely applied to evaluate the sources of heavy metals in soils. The PMF model analyzes and quantifies the contributions of different 
pollution sources to samples. There have been numerous studies that systematically analyzed the pollution status of heavy metals in soils by combining geostatistical methods with the EPA's PMF model $[14,17,18]$.

Coal mining, grinding, coal transportation, and coal combustion processes are known to transfer several heavy metals to the topsoil, leading to contamination of heavy metals in mining regions [19-21]. Tang et al. [18] reported concentration levels of heavy metals in soils in Fuxin, China. The mean concentrations of $\mathrm{As}, \mathrm{Cd}, \mathrm{Cr}, \mathrm{Ni}$, and $\mathrm{Zn}$ all exceeded the soil background values of these heavy metals. In fact, the mean concentration of $\mathrm{Cd}$ was nine times higher than its background value. In contrast, the mean concentrations of $\mathrm{Cu}, \mathrm{Hg}$, and $\mathrm{Pb}$ were lower than their respective background values. Sun et al. [22] studied the concentrations of heavy metals in soils of Tangshan, China. The mean concentrations of $\mathrm{Zn}, \mathrm{Pb}, \mathrm{Cd}, \mathrm{Hg}$, and $\mathrm{Cu}$ were higher than their background values, while those of $\mathrm{Cr}, \mathrm{Ni}$, and As were lower than their background values. None of them exceeded their corresponding Grade II values defined by the Chinese Soil Environmental Quality Standard. Hua et al. [23] measured the concentrations of heavy metals in soils of Daye, China. The mean concentrations of $\mathrm{Cd}, \mathrm{Cu}, \mathrm{Pb}$, and $\mathrm{Zn}$ were higher than their background values, while $\mathrm{Cr}, \mathrm{Ni}$, and $\mathrm{Mn}$ concentrations were not. The mean concentration of $\mathrm{Cd}$ was seven times higher than its background value. Liang et al. [14] investigated average contents of twelve heavy metals ( $\mathrm{Zn}, \mathrm{Cd}, \mathrm{Cu}, \mathrm{Hg}, \mathrm{Pb}, \mathrm{Sb}, \mathrm{As}, \mathrm{Mo}, \mathrm{V}, \mathrm{Fe}$, and $\mathrm{Cr}$ ); except for $\mathrm{Mn}$, all exceeded their background levels in soils in Hunan Province. In fact, in Lianyuan, the $\mathrm{Hg}$ level was higher than its corresponding Grade II value defined by the Chinese Soil Environmental Quality Standard. Reza et al. [16] researched the average contents of heavy metals in a mining area of northwest India. The mean concentrations of $\mathrm{Cr}, \mathrm{Cd}, \mathrm{Ni}$, and $\mathrm{Pb}$ were $112.3 \mathrm{mg} / \mathrm{kg}, 2.60 \mathrm{mg} / \mathrm{kg}, 87.5 \mathrm{mg} / \mathrm{kg}$, and $183.1 \mathrm{mg} / \mathrm{kg}$, respectively. Overall, the degree of soil polluted by heavy metals varies significantly in different coal mining cities. Furthermore, the sources contribution was dominated by anthropogenic activities. In contrast to other land-use areas [17, 24, 25], studies of heavy metal pollution in soils of coal mining areas are relatively few at present. Therefore, the existing information on heavy metals in soils of coal mining areas is clearly inadequate for researchers and managers to comprehensively evaluate their contamination levels and potential risks.

Wuhai is a typical coal mining city within the Inner Mongolia Autonomous Region, China. There are 3.147 billion tons of coal reserves in Wuhai, of which more than 0.5 billion tons of coal have been excavated. The development of chemical, coal, iron, and steel production and other industries has likely led to the deterioration of soil quality in Wuhai [26]. However, the pollution status of heavy metals in soils in Wuhai has not been investigated to date.

The main objectives of this study were (1) to report contamination levels of eight heavy metals, namely, As, $\mathrm{Hg}$, $\mathrm{Cr}, \mathrm{Ni}, \mathrm{Cu}, \mathrm{Zn}, \mathrm{Cd}$, and $\mathrm{Pb}$; (2) to ascertain spatial distribution characteristics using geostatistics and the ordinary kriging interpolation method; and (3) to quantitatively identify sources of heavy metals in soils by using the EPA's PMF model.

\section{Materials and Methods}

2.1. Study Area. Wuhai $\left(39^{\circ} 02^{\prime} 30^{\prime \prime}-39^{\circ} 54^{\prime} 5^{\prime \prime} \mathrm{N} ; 106^{\circ} 36^{\prime}\right.$ $25^{\prime \prime}-107^{\circ} 08^{\prime} 05^{\prime \prime} \mathrm{E}$ ) is located in the southwest of the Inner Mongolia Autonomous Region, adjacent to the Ningxia Hui Autonomous Region, and at the junction of three deserts-the Wulanbuhe, the Kubuqi, and the Maowusu. The Yellow River crosses the region from south to north along its eastern edge. The city covers an area of around $1754 \mathrm{~km}^{2}$, encompassing three administrative districts-Haibowan, Wuda, and Hainan. The city terrain is the highest on its east and west sides and the lowest at its center. Average annual precipitation and evaporation are 160 and $3500 \mathrm{~mm}$, respectively. The diurnal temperature $\left(-36.6^{\circ} \mathrm{C}-40.2^{\circ} \mathrm{C}\right)$ varies greatly, which is characteristic of its typical continental climate. Wuhai has abundant coal resources, comprising mainly bituminous and coking coals. Its industries are centered on coal mining, chemistry, electric power generation, and building materials. As an emerging energy city, its heavy metal soil contamination is closely related to its rapid industrial development.

\subsection{Sample Collection and Concentration Determination.}

A total of 58 surface soil samples were collected from Wuhai during 25 to 28 July, 2019 (Figure 1). Sampling sites were selected using a grid, with a density of about one sample every $3-5 \mathrm{~km}[27,28]$. To ensure that the sampling sites represented the soil quality of the entire monitoring area, the land-use status and geological information were documented to establish context. The sampling sites covered the coal mining area, both sides of the Yellow River, near the main highway, beside a factory, as well as farmland, grassland, and desert areas. All of the soil samples were collected from the $0-20 \mathrm{~cm}$ topsoil horizon, using a stainless spade [29]. They were immediately sealed in polyethylene plastic bags to avoid contamination and labeled. The latitude and longitude of each sampling point were recorded using a GPS, and any relevant environmental information pertaining to the sample site was recorded.

Sand $(0.05-2 \mathrm{~mm})$ was the dominant soil particles in the $0-20 \mathrm{~cm}$ soil profiles in the study area. Thus, all samples were dried in open air at room temperature in a laboratory and sieved through a $2 \mathrm{~mm}$ sieve, after removing gravel and plant materials [30]. The processed samples were sealed in polyethylene plastic bags for concentration determination. The determination of $\mathrm{Cr}, \mathrm{Ni}, \mathrm{Cu}, \mathrm{Zn}, \mathrm{Cd}$, and $\mathrm{Pb}$ was carried out according to the method outlined in HJ803-2016; Hg was determined according to the method outlined in DZ/ T0279.17-2016; and Arsenic (As) was determined according to the method outlined in DZ/T0279.13-2016. The concentrations of $\mathrm{Cr}, \mathrm{Cd}, \mathrm{Pb}, \mathrm{Cu}, \mathrm{Zn}$ and $\mathrm{Ni}$ were analyzed by inductively coupled plasma mass spectrometry; while $\mathrm{Hg}$ and As were measured using atomic fluorescence spectrometry. The accuracy of the elemental analyzes was verified using standard reference materials: GSD-31, GSS-32, GSS-33 and GSS-34. The results showed that the recoveries of these eight heavy metals were within the range 94.6\%-106.8\%. Each set of ten samples included one duplicate sample, and 


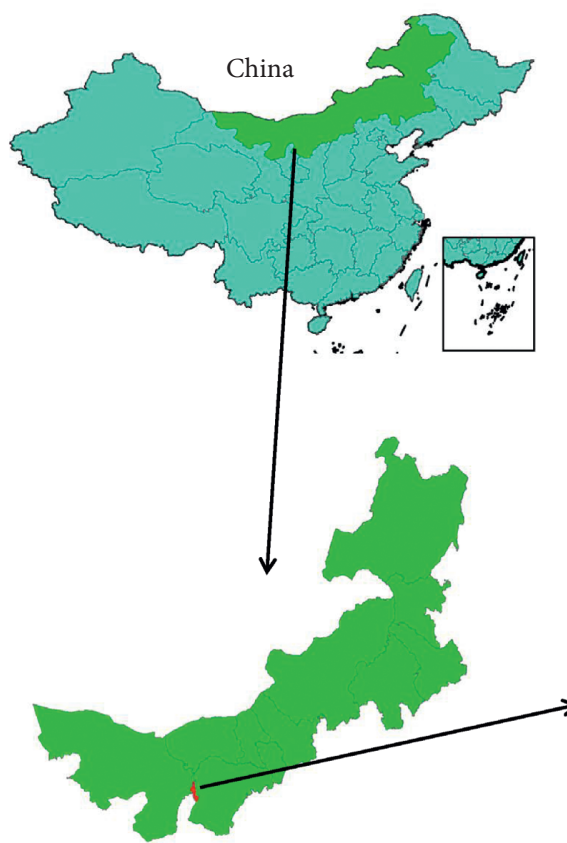

Inner Mongolia autonomous region

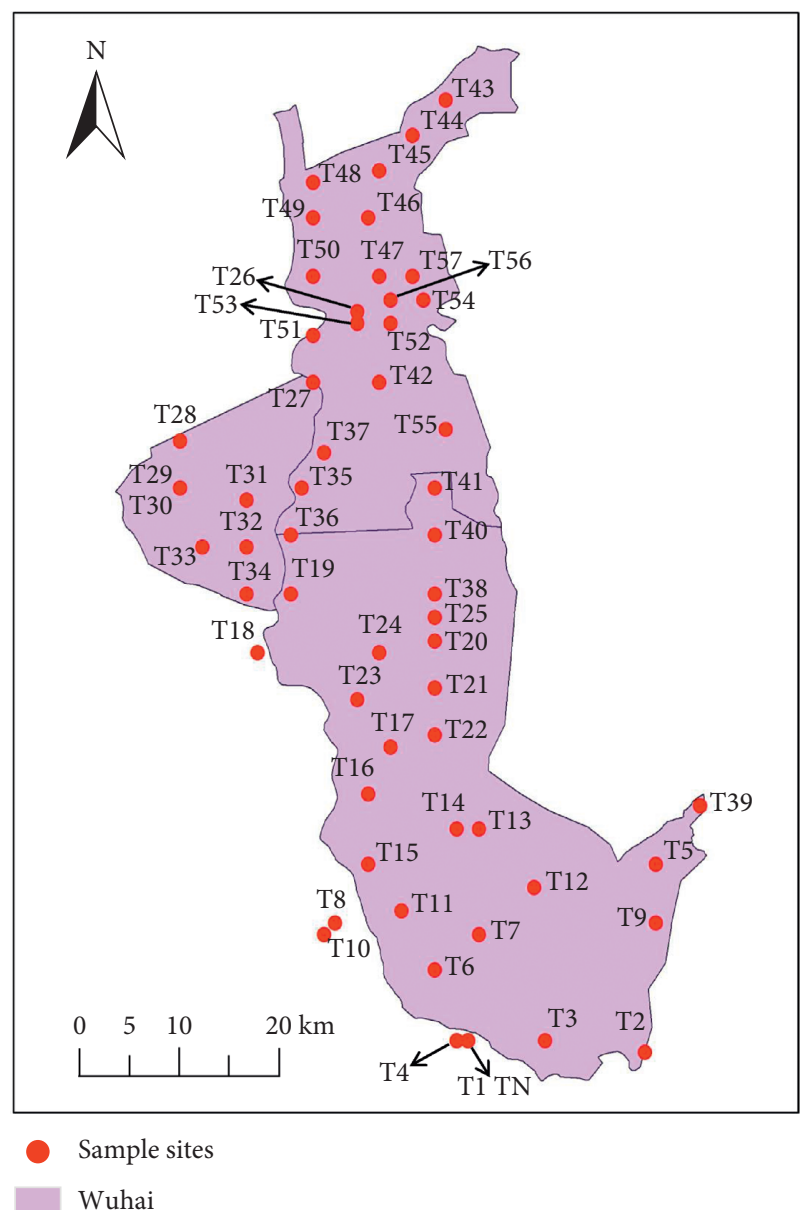

Wuhai

FIgURE 1: Location of study area and distribution of sampling sites.

relative standard deviations were lower than $15 \%$ for all batch treatments. Method detection limits (MDLs) were 1, $0.0005,5,1,1,4,0.02$, and $0.5 \mathrm{mg} / \mathrm{kg}$ for $\mathrm{As}, \mathrm{Hg}, \mathrm{Cr}, \mathrm{Ni}, \mathrm{Cu}$, $\mathrm{Zn}, \mathrm{Cd}$, and $\mathrm{Pb}$, respectively.

\subsection{Data Analysis}

2.3.1. Descriptive Statistical Analysis. SPSS 24.0 software (IBM Corp., Armonk, NY, USA) was used for basic descriptive statistical analysis of the sample data. This provided the maximum, minimum, mean, standard deviation, coefficient of variation, skewness, and kurtosis and allowed us to assess the normality for the sampled heavy metal concentrations. The correlations between heavy metals were assessed using Pearson's correlation method.

2.3.2. Geostatistical Analysis. Geostatistical analysis is based on regional variable theory and is used to study distribution characteristics and variation with geographic properties. Meanwhile, a semivariogram model was used to interpolate unknown points, as an important complementary tool [31]. In this study, ArcGIS 10.2 (Esri, Inc., Redlands, CA, USA) was used for calculating the spatial distribution characteristics of soil heavy metals using the ordinary kriging interpolation method [32]. The original concentration data, which did not meet the conditions of a normal distribution, were normalized using a logarithm transformation, and a normality test was carried out using a Q-Q plot. The semivariogram model and kriging calculation method are defined as follows [33]:

$$
\begin{aligned}
\gamma(h) & =\frac{1}{2 N(h)} \sum_{i=1}^{N(h)}\left[Z\left(x_{i}\right)-Z\left(x_{i}+h\right)\right]^{2}, \\
\widehat{Z}\left(x_{0}\right) & =\sum_{i=1}^{N} \lambda_{i} Z\left(x_{i}\right),
\end{aligned}
$$

where $\gamma(h)$ is semivariogram, $h$ is the step length or distance, $N(h)$ is the number of pairs of sample points separated by $h$. $Z\left(x_{i}\right)$ is the measured value of heavy metals in the soil at the regionalized variable position $x_{i}, \widehat{Z}\left(x_{0}\right)$ is the concentration of the heavy metal to be tested, $n$ is the number of sampling points, and $\lambda_{i}$ is the set of weight coefficients. The semivariogram model includes linear, spherical, exponential, and Gaussian components. In ordinary kriging space interpolation, the optimal fitting model improves the accuracy of interpolation. 
2.4. Positive Matrix Factorization Model. The EPA's PMF 5.0 is a modified factor analysis receptor model, proposed by Paatero [34]. It has been successfully applied to determine the source apportionment of various types of environmental pollution. In our study, EPA's PMF 5.0 was used to determine the source apportionment of heavy metals in local soils. According to the EPA's PMF 5.0 user guide,

$$
x_{i j}=\sum_{k=1}^{p} g_{i k} f_{k j}+e_{i j} \text {, }
$$

where $x_{i j}$ is the measurement matrix of the $j$ th heavy metal element in $i$ number of samples; $g_{i k}$ is a contribution matrix of the $k$ th source factor for $i$ number of samples; $f_{k j}$ is a source profile of $j$ th heavy metal element for the $k$ th source factor; and $e_{i j}$ refers to the residual value for the $j$ th metal element in $i$ number of samples. The minimum value of the objective function $Q$ can be computed by the following formula:

$$
Q=\sum_{i=1}^{n} \sum_{j=1}^{m}\left(\frac{x_{i j}-\sum_{k=1}^{p} g_{i k} f_{k j}}{u_{i j}}\right)^{2},
$$

where $u_{i j}$ refers to the uncertainty in the $j$ th heavy metal element for sample $i$. The remarkable feature of PMF is that it uses uncertainty to analyze the quality of all individual concentration data points. If the concentration of heavy metal does not exceed the MDL value, then the uncertainty is calculated using the following formula:

$$
\mathrm{Unc}=\frac{5}{6} \times \mathrm{MDL}
$$

while if the concentration of heavy metal exceeds its corresponding MDL value, then the uncertainty is calculated using this formula:

$$
\mathrm{Unc}=\sqrt{(\text { Error fraction } \times \text { concentration })^{2}+(0.5 \times \mathrm{MDL})^{2}} .
$$

\section{Results and Discussion}

3.1. Levels of Heavy Metal Contamination. The statistical characteristics of concentrations of As, $\mathrm{Hg}, \mathrm{Cr}, \mathrm{Ni}, \mathrm{Cu}, \mathrm{Zn}$, $\mathrm{Cd}$, and $\mathrm{Pb}$ in all soil samples are presented in Table 1 . In this study, the soil background values for the Inner Mongolia Autonomous Region were used as evaluation criteria [35]. In addition, the concentrations of heavy metals in soils were compared with Grade I and Grade II values of the Chinese Soil Environmental Quality Standard (GB15618-1995). The mean concentrations of $\mathrm{As}, \mathrm{Hg}, \mathrm{Cr}, \mathrm{Ni}, \mathrm{Cu}, \mathrm{Zn}, \mathrm{Cd}$, and $\mathrm{Pb}$ in soils were $9.31 \mathrm{mg} / \mathrm{kg}, 0.12 \mathrm{mg} / \mathrm{kg}, 61.7 \mathrm{mg} / \mathrm{kg}, 24.7 \mathrm{mg} / \mathrm{kg}$, $19.6 \mathrm{mg} / \mathrm{kg}, 55.2 \mathrm{mg} / \mathrm{kg}, 0.16 \mathrm{mg} / \mathrm{kg}$, and $28.0 \mathrm{mg} / \mathrm{kg}$, respectively. Generally, the mean concentrations of heavy metals in the soils were all lower than their Grade I values defined in the Chinese Soil Environmental Quality Standard, although they exceeded their background values. The exceedance ratios of $\mathrm{As}, \mathrm{Hg}, \mathrm{Cr}, \mathrm{Ni}, \mathrm{Cu}, \mathrm{Zn}, \mathrm{Cd}$, and $\mathrm{Pb}$ were $100 \%, 29.3 \%, 100 \%, 98.3 \%, 96.6 \%, 39.6 \%, 100 \%$, and $100 \%$, respectively. The most serious heavy metal contaminations were associated with $\mathrm{Hg}$ and $\mathrm{Cd}$; these species had mean concentrations that exceeded their background values by 4.3 and 4.2 times, respectively. This is consistent with previously published statements that $\mathrm{Hg}$ and $\mathrm{Cd}$ produce the most serious heavy metal contaminations in China $[14,22,36]$.

The coefficients of variation of $\mathrm{As}, \mathrm{Hg}, \mathrm{Cr}, \mathrm{Ni}, \mathrm{Cu}, \mathrm{Zn}$, $\mathrm{Cd}$, and $\mathrm{Pb}$ were $24.7 \%, 540 \%, 15.9 \%, 22.6 \%, 71.5 \%$, $81.2 \%, 48.3 \%$, and $139 \%$, respectively (Table 1 ). The variability of heavy metal concentrations was ranked: $\mathrm{Hg}>\mathrm{Pb}>\mathrm{Zn}>\mathrm{Cu}>\mathrm{Cd}>\mathrm{As}>\mathrm{Ni}>\mathrm{Cr}$. Therefore, $\mathrm{Hg}, \mathrm{Pb}$, $\mathrm{Zn}, \mathrm{Cu}$, and $\mathrm{Cd}$ had higher coefficients of variation and wider concentration ranges than other heavy metals. Soil samples revealed very heterogeneous spatial distributions of these metals, indicating that their concentrations were strongly influenced by anthropogenic sources [37]. In contrast, As, Cr, and Ni had relatively low coefficients of variation, suggesting that these heavy metals were less affected by anthropogenic sources.

Table S1 shows a comparison of recently published heavy metal concentrations in soils from typical coal mining cities and nonmining cities throughout China. When compared to data for other typical coal mining cities, our results indicate that soil concentrations of $\mathrm{As}, \mathrm{Cr}, \mathrm{Ni}, \mathrm{Cu}$, and $\mathrm{Pb}$ represent moderate contamination levels; the soil concentration of $\mathrm{Hg}$ represents a high contamination level, while soil concentrations of $\mathrm{Zn}$ and $\mathrm{Cd}$ represent low contamination levels. When compared to other studies conducted in nonmining cities, the concentrations of $\mathrm{As}, \mathrm{Hg}, \mathrm{Cr}, \mathrm{Ni}$, and $\mathrm{Pb}$ represent moderate contamination levels, while $\mathrm{Cu}, \mathrm{Zn}$, and $\mathrm{Cd}$ represent low contamination levels. Additionally, a comparison of heavy metal concentrations in soils was also made between studies conducted in typical coal mining cities and nonmining cities. The results show that concentrations of $\mathrm{Hg}$ in mining cities were slightly lower than those in nonmining cities, but concentrations of $\mathrm{As}, \mathrm{Cr}, \mathrm{Ni}, \mathrm{Cu}, \mathrm{Zn}, \mathrm{Cd}$, and $\mathrm{Pb}$ were not significantly different among cities.

The above discussion indicates that heavy metals in soils of Wuhai have been contaminated to different degrees, with $\mathrm{Hg}$ and $\mathrm{Cd}$ pollution being more severe than for other heavy metals. $\mathrm{Hg}, \mathrm{Pb}, \mathrm{Zn}, \mathrm{Cu}$, and $\mathrm{Cd}$ showed more spatial variation than other heavy metals. According to our comparison of concentrations of heavy metals in Chinese coal mining cities and nonmining cities, heavy metal concentrations in soils of Wuhai represent moderate contamination. Therefore, it is necessary to analyze the spatial distribution characteristics to determine the heavy metal sources within this region.

\subsection{Spatial Distributions of Heavy Metal Concentrations.} The spatial distributions of heavy metal concentrations in the soils of Wuhai are shown in Figure 2. Generally, the spatial trends of heavy metals within the study area are as follows: the degree of heavy metal pollution is the highest in the middle to western parts of Wuhai, with lower degrees of pollution to the south and north. In the midwestern part of Wuhai, there are mainly coalfields and a major highway. In the south of Wuhai, there are various infrastructure and land-use types, including a gas company, a cement plant, a 
TABLE 1: The statistical characteristics of concentrations of soil heavy metals in Wuhai (mg/Kg).

\begin{tabular}{|c|c|c|c|c|c|c|c|c|}
\hline Element & Mean & Max & Min & $\mathrm{SD}$ & CV (\%) & Background $^{\mathrm{a}}$ & Grade I $^{\mathrm{b}}$ & Grade $\mathrm{II}^{\mathrm{c}}$ \\
\hline As & 9.31 & 16.8 & 6.37 & 2.30 & 24.7 & 6.30 & 15 & 30 \\
\hline $\mathrm{Hg}$ & 0.12 & 4.95 & 0.01 & 641 & 539 & 0.028 & 0.15 & 0.5 \\
\hline $\mathrm{Cr}$ & 61.7 & 104 & 44.7 & 9.81 & 15.9 & 36.50 & 90 & 200 \\
\hline $\mathrm{Ni}$ & 24.7 & 58.3 & 16.2 & 5.58 & 22.6 & 17.30 & 40 & 50 \\
\hline $\mathrm{Cu}$ & 19.6 & 122 & 12.1 & 14.0 & 71.5 & 12.90 & 35 & 100 \\
\hline $\mathrm{Zn}$ & 55.2 & 371 & 29.4 & 44.8 & 81.2 & 48.60 & 100 & 250 \\
\hline $\mathrm{Cd}$ & 0.16 & 0.50 & 0.06 & 0.08 & 48.3 & 0.037 & 0.2 & 0.3 \\
\hline $\mathrm{Pb}$ & 28.0 & 316 & 15.2 & 38.8 & 139 & 15.00 & 35 & 300 \\
\hline
\end{tabular}

${ }^{\mathrm{a}}$ Soil background values in Inner Mongolia Autonomous Region. ${ }^{\mathrm{b}}$ Grade I of the Chinese Soil Environmental Quality Standard (GB15618-1995). ${ }^{\mathrm{c}}$ Grade II of the Chinese Soil Environmental Quality Standard, $6.5<\mathrm{pH}<7.5$ (GB15618-1995).
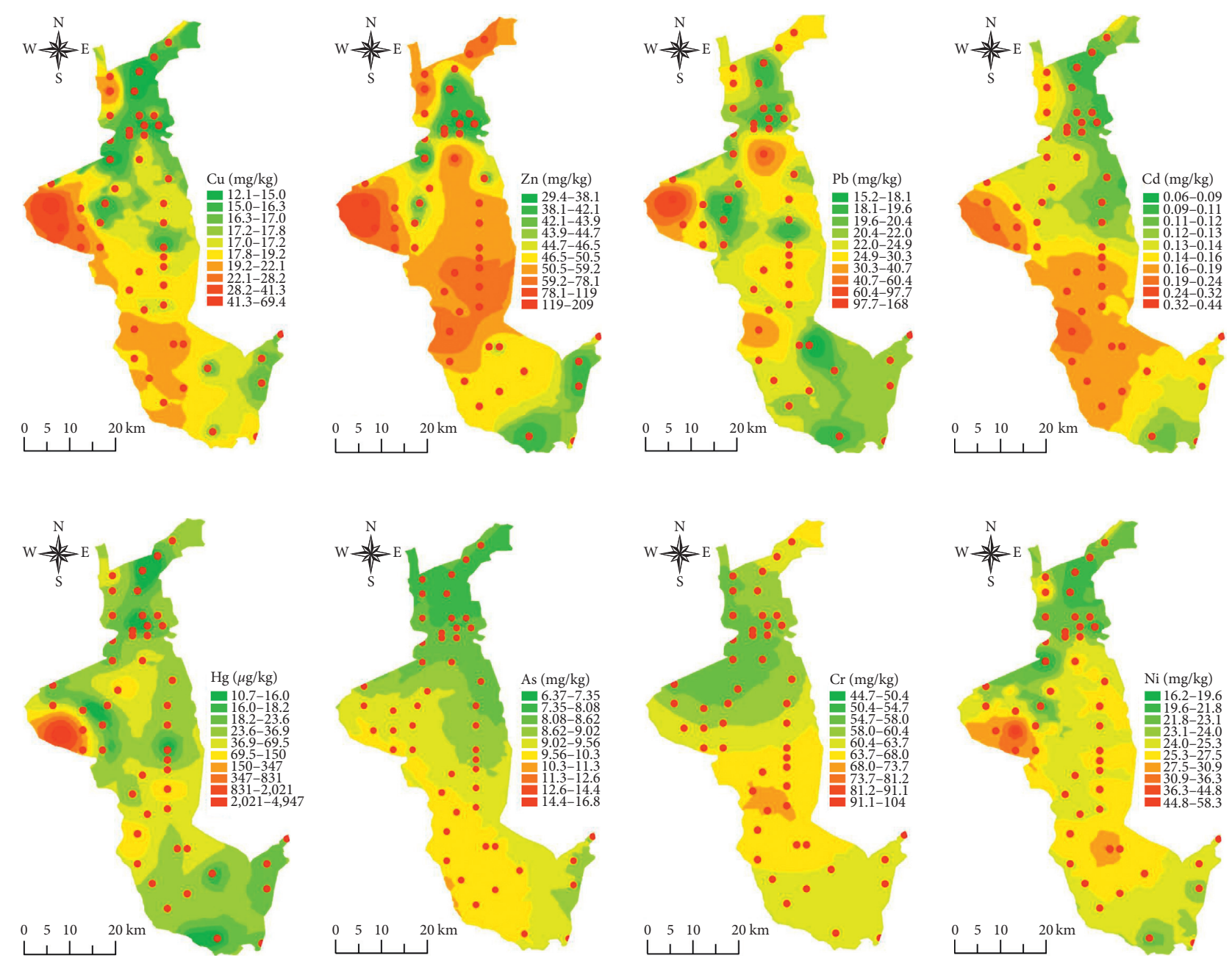

FIgURE 2: Spatial distribution of heavy metal concentrations in soils.

petrol station, and various expressways, as well as large areas of farmland and grassland. In the north of Wuhai, there are expressways and plastic manufacturing and coal chemical engineering plants. Heavy pollution of $\mathrm{Hg}, \mathrm{Ni}, \mathrm{Cu}, \mathrm{Zn}, \mathrm{Cd}$, and $\mathrm{Pb}$ was found in samples that were located in the midwestern part, proximal to the Wuhushan coalfield in the Wuda district of Wuhai. In this region, there are coal mining and coal transportation activities. Clearly, coal mining activities made a significant contribution to heavy metal contamination of soils in the midwestern part of Wuhai.

Spatial distributions of $\mathrm{Cu}$ and $\mathrm{Zn}$ in soils were highly similar, indicating that $\mathrm{Cu}$ and $\mathrm{Zn}$ may originate from the same source. Large areas having soils contaminated with $\mathrm{Cu}$ and $\mathrm{Zn}$ were situated in the midwestern, northern, and southwestern parts of Wuhai. In the midwestern area, high concentrations of $\mathrm{Cu}$ and $\mathrm{Zn}$ were proximal to the coalfield 
and the highway, close to coal chemical industries and plastic manufacturing enterprises in the north, and close to a gas company, a cement plant, a gas station and expressways in the south. We speculate that $\mathrm{Cu}$ and $\mathrm{Zn}$ contamination of the soil were caused by industrial emissions, vehicle exhaust, and mechanical deterioration particles, which were later dispersed and deposited by atmospheric processes $[13,38,39]$.

The $\mathrm{Pb}$ hotspots were located in midwestern and southwestern parts of Wuhai, as well as within the central Haibowan district of Wuhai. These areas were proximal to the major highway and surrounding coalfields. The highest concentration area was associated with the highway. Vehicle exhaust and coal dust were likely important sources of $\mathrm{Pb}$ $[40,41]$. This indicates that $\mathrm{Cu}, \mathrm{Zn}$, and $\mathrm{Pb}$ inputs to soils mainly occurred via atmospheric deposition.

The hotspots of $\mathrm{Cd}$ in soils were mainly distributed in the midwestern and southwestern parts of Wuhai. In the midwestern area, Cd was associated with the highway and surrounding coalfield. Therefore, coal mining and its associated activities are likely the primary contributors to $\mathrm{Cd}$ contamination [42]. Elsewhere, the Cd distributions coincided with $\mathrm{Pb}$ distributions, especially in the southwest. This suggests a similar dispersion of $\mathrm{Cd}$ and $\mathrm{Pb}$, related to a similar source. Vehicle exhaust could contribute both $\mathrm{Cd}$ and $\mathrm{Pb}$ inputs to soils $[13,43]$. However, other large-scale areas with moderate concentrations of $\mathrm{Cd}$ were present in southern to central areas of Wuhai. These areas host numerous industrial activities, linked to a gas company, a gas station, and a cement plant. These industries have been previously linked to Cd contamination in soils [44]. $\mathrm{Cd}$ and Zn had zonal distributions toward the southwest, along the Yellow River, possibly related to fluvial processes. Pavolvic et al. reported that both $\mathrm{Cd}$ and $\mathrm{Zn}$ have high potential for adhering to clay minerals and are readily transported by rivers. This may lead to their accumulation in riparian soils [45].

The hotspots of $\mathrm{Hg}$ were in the midwestern part of Wuhai. In this region, $\mathrm{Hg}$ had an extreme value of more than 60 times the background value, far exceeding its Grade II value. Given the long history of coal mining in this area, it is likely that large spoil quantities have been generated, which release $\mathrm{Hg}$-rich effluents into the surrounding environment [22]. Moreover, other moderately polluted areas were scattered in central and southern parts of Wuhai, associated with the gas company, the gas station, and the expressways. Previous studies have indicated that petrochemical plants are a major source of $\mathrm{Hg}$ [46]. Clearly, the $\mathrm{Hg}$ distribution was predominantly influenced by coal mining and the local petrochemical industry $[42,47]$.

Arsenic (As) concentrations increased continually from northeast to southwest, with hotspots of Arsenic (As) situated on the southwest limit of Wuhai within farmland and a village. A number of reports have identified Arsenic (As) as originating from agricultural pesticides and fertilizers $[48,49]$. In this region, Arsenic (As) contamination in soils was also likely related to agricultural activities.

High concentrations of $\mathrm{Cr}$ were documented in the central Hainan district of Wuhai, related to both the coalfield and the local cement plant. A Ni hotspot, located in the midwestern part of Wuhai, was also associated with coal mining. In addition to the hotspot in the midwestern area, another Ni hotspot occurred within the southern to central desert area, having no obvious point sources of Ni. The coefficients of variation and spatial variances of $\mathrm{Cr}$ and $\mathrm{Ni}$ were both relatively low. This indicates that $\mathrm{Cr}$ and $\mathrm{Ni}$ levels in soils were primarily controlled by parent materials [50].

Overall, the spatial distributions of $\mathrm{Cu}, \mathrm{Zn}$, and $\mathrm{Pb}$ were mainly affected by atmospheric deposition of airborne particles; $\mathrm{Hg}$ was mainly related to coal mining; $\mathrm{Cd}$ was mainly related to industrial activities; Arsenic (As) was mainly related to agricultural activities; and $\mathrm{Cr}$ and $\mathrm{Ni}$ were mainly related to parent materials of the soils. Furthermore, spatial distribution of soil heavy metals is rarely influenced by transport in the atmosphere since sand has the highest fractions in the research area. The sources of these heavy metals are discussed in detail below.

3.3. Source Apportionment of Heavy Metals. Pearson's correlation coefficients of the eight heavy metals are shown in Table S2. Strong correlations were found between $\mathrm{Pb}$ and $\mathrm{Cu}$, $\mathrm{Zn}, \mathrm{Cd}(p<0.01)$, while pairs $\mathrm{Ni}$ and $\mathrm{Cr}, \mathrm{Cu}$ and As were slightly correlated $(p<0.05)$. Hg did not display a correlation with any other heavy metals. Significant correlations between metal elements in soils suggest that they had similar contamination sources. For example, $\mathrm{Cu}, \mathrm{Zn}$, and $\mathrm{Pb}$ may be derived from the same source $(r>0.9)$, as reported by $\mathrm{Ma}$ et al. [13]. Given the complexity of heavy metal pollution in soils related to human activities, the conclusions based on our Pearson's correlation coefficient analysis are not comprehensive. Therefore, the EPA's PMF model was used to identify and quantify the contribution rates of different pollution sources in the study area. Results are shown in Figure 3.

Factor 1 was dominated by $\mathrm{Hg}(74.0 \%)$ and $\mathrm{Cd}(43.5 \%)$. The high coefficient of variation for $\mathrm{Hg}(540 \%)$ indicates that $\mathrm{Hg}$ pollution is significantly affected by human activities. It has been reported that $\mathrm{Hg}$ in soils mainly originates from industrial sources, especially petrochemical production and coal combustion $[46,51,52]$. Similarly, Cd also enters the environment through human activities, via exhaust gas and coal combustion emissions, owing to the stable bond between $\mathrm{Cd}$ and organic matter and sulfide in coal $[53,54]$. These sources are consistent with the distributions observed in our study. A large number of coal mines are exploited around Wuhai to provide energy for thermal power, iron and steel production, and cement production plants. Coal is also extensively used as a raw material in the coal chemical industry and in metal smelting [55]. In general, the concentrations of $\mathrm{Hg}$ and $\mathrm{Cd}$ in soils are mainly related to industrial activities, especially coal mining, coal chemical engineering, and metal smelting. Therefore, Factor 1 reflects the input from industrial activities.

Factor 2 was dominated by Arsenic (As) (69.7\%). Arsenic (As) is commonly used in fertilizers as an additive $[56,57]$; therefore, it is routinely introduced into soils during fertilizer applications. Arsenic (As) also is an effective 

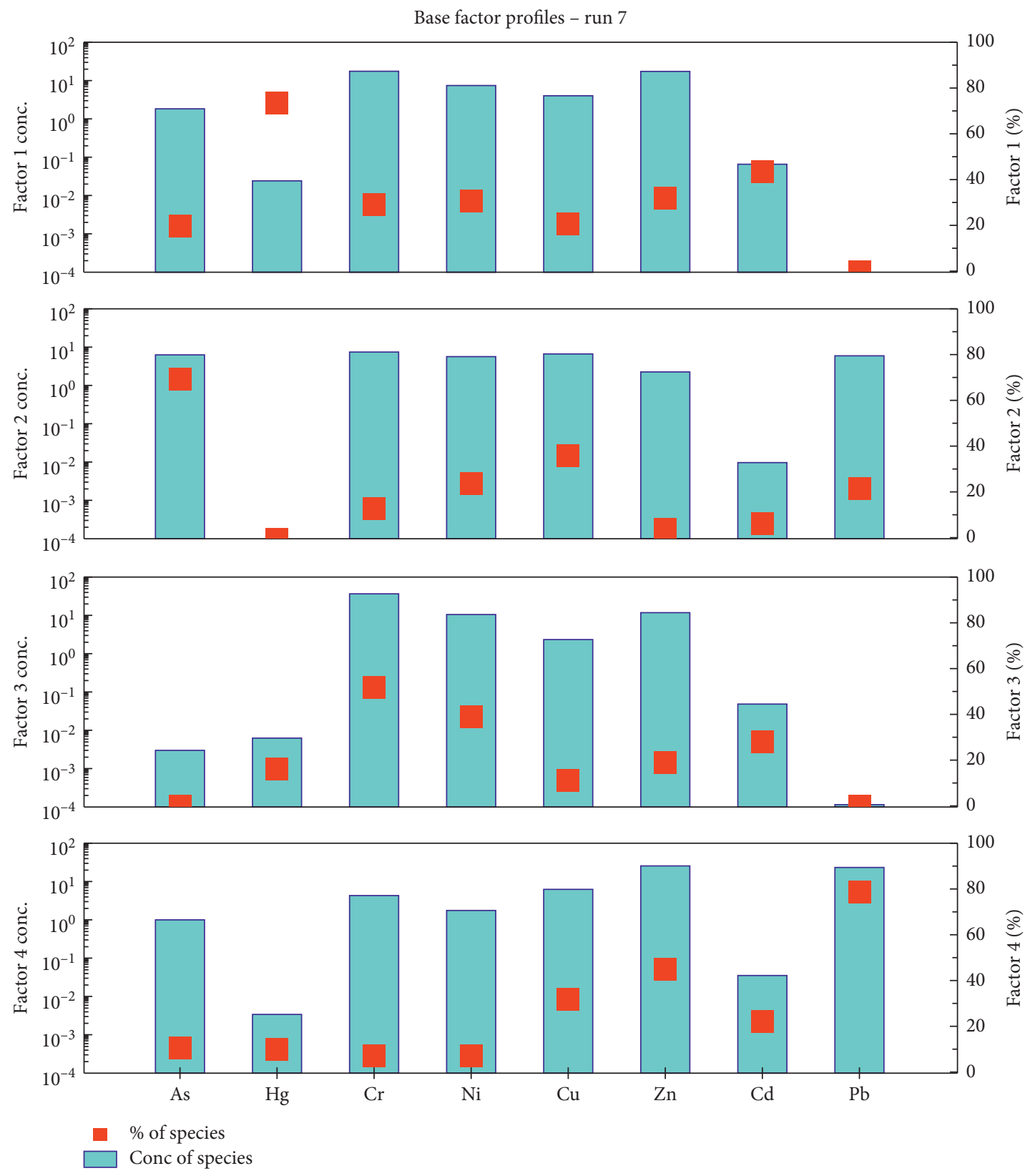

FIGURE 3: Factor profiles from PMF model using soil heavy metal concentration data.

ingredient in various herbicides and pesticides used regularly in agricultural production [58, 59]. Animal excrement may be another source of Arsenic (As), because antibiotics used for poultry contain it [60]. Clearly, Arsenic (As) is mainly linked to agricultural activities, occurring within the large area of farmland and grassland in the southwestern part of the study area. These long-term activities may lead to ongoing enrichment of Arsenic (As) in local soils, which will aggravate local Arsenic (As) pollution. Therefore, Factor 2 reflects the input of agricultural activities.

Factor 3 was dominated by $\mathrm{Cr}(51.2 \%)$ and $\mathrm{Ni}(38.6 \%)$. Our descriptive statistical analysis revealed small coefficients of variation for both $\mathrm{Cr}$ and $\mathrm{Ni}$, with similar concentrations measured between background and sample values. Differences in concentration between $\mathrm{Cr}$ and $\mathrm{Ni}$ may be related to variability in the parent materials of the soils. Previous studies have shown that variations in $\mathrm{Cr}$ and $\mathrm{Ni}$ in different soils are inherited from the parent material $[15,22,61]$. Hence, Factor 3 reflects inputs from mainly natural sources.

Factor 4 was weighted on $\mathrm{Pb}(78.4 \%), \mathrm{Zn}$ (44.7\%), and $\mathrm{Cu}(32.0 \%)$, which are all affected by human activities, according to our descriptive statistical analysis. Many previous studies reported that the main sources of $\mathrm{Pb}$ in soils are vehicle exhaust emissions and coal combustion [62-64]. Gao et al. found that $\mathrm{Pb}$ and $\mathrm{Zn}$ were derived from atmospheric deposition of dust from open pit coal mines [65]. Li et al. found that $\mathrm{Cu}, \mathrm{Zn}$, and $\mathrm{Pb}$ were all released in the smelting process of sulfide minerals (sphalerite and galena) [15]. Given the abundant coal resources and the long-term 
mining and processing operations in the study area, several heavy metals contained in the coal enter the environment as dust. In addition, heavy metals contained in flue gas are discharged into the atmosphere by many coal-burning industries; these enter the soil via wet and dry deposition processes. Furthermore, growth in the transport sector within the study area has resulted in a large amount of vehicle emissions containing $\mathrm{Pb}$; this $\mathrm{Pb}$ constantly enters the soil via atmospheric deposition. Thus, Factor 4 reflects the contribution of atmospheric deposition.

To summarize, $\mathrm{Hg}$ and $\mathrm{Cd}$ point to sources of industrial activities, while $\mathrm{Cu}, \mathrm{Zn}$, and $\mathrm{Pb}$ are indicators of sources of atmospheric deposition. Moreover, arsenic (As) is indicative of the sources of agricultural activities, while $\mathrm{Cr}$ and Ni point to natural sources. Based on the factor fingerprint of each heavy metal, the overall percent contribution of each source was computed. Industrial activities (31.3\%) contributed most of the heavy metal content to Wuhai soils, followed by atmospheric deposition (26.3\%), agricultural activities (21.9\%), and natural sources (20.5\%). Overall, anthropogenic sources were the predominant factors, reflecting inputs from coal mining, coal chemical engineering, metal smelting, coal burning, vehicle emissions, fertilization, pesticide spraying, and other activities, yielding a total contribution of approximately $80 \%$.

\section{Conclusions}

This study investigated contamination levels, spatial distribution characteristics, and percentage contributions of various sources of heavy metals in soils in Wuhai, China, by using descriptive statistical analysis, ordinary kriging interpolation, and EPA's PMF model. Generally, mean concentrations of heavy metals in soils in Wuhai exceeded their background values, with exceedance ratios of $\mathrm{As}, \mathrm{Hg}, \mathrm{Cr}, \mathrm{Ni}$, $\mathrm{Cu}, \mathrm{Zn}, \mathrm{Cd}$, and $\mathrm{Pb}$ being $100 \%, 29.3 \%, 100 \%, 98.3 \%, 96.6 \%$, $39.6 \%, 100 \%$, and $100 \%$, respectively. Their coefficients of variation ranged from $15.9 \%$ to $540 \%$. The most serious heavy metal contaminations in this area were associated with $\mathrm{Hg}$ and $\mathrm{Cd}$. According to comparisons between soils from typical coal mining and nonmining cities throughout China, Wuhai soils were moderately contaminated by heavy metals. Spatial distributions and source apportionment suggest that heavy pollution levels of $\mathrm{Hg}, \mathrm{Ni}, \mathrm{Cu}, \mathrm{Zn}, \mathrm{Cd}$, and $\mathrm{Pb}$ proximal to the Wuhushan coalfield of the Wuda district of Wuhai are linked to significant inputs from coal mining activities. Meanwhile, $\mathrm{Cu}, \mathrm{Zn}$, and $\mathrm{Pb}$ contaminations were mainly derived from fuel and coal combustion followed by atmospheric deposition. $\mathrm{Hg}$ and $\mathrm{Cd}$ contaminations were mainly derived from industrial activities, including coal mining, coal chemical engineering, and metal smelting. The Arsenic (As) contamination was mainly related to agricultural activities, with inputs from fertilizers, herbicides, pesticides, and animal excrement. In contrast, parent materials played a vital role in producing $\mathrm{Cr}$ and $\mathrm{Ni}$ enrichments in these soils. Generally, anthropogenic sources were the predominant factors influencing heavy metal pollution in this area.

\section{Data Availability}

The numerical data used to support the findings of this study are included within the article and the associated supporting information.

\section{Conflicts of Interest}

The authors declare that they have no conflicts of interest.

\section{Acknowledgments}

This work was cosupported by the National Key R\&D Program of China (2017YFC0504401), the National Natural Science Foundation of China (21777188), and the Fundamental Research Funds for the Central Universities in China (2015QH02). Q. B. was financially supported by Yue Qi Young Scholar Project, China University of Mining \& Technology, Beijing (2017QN15).

\section{Supplementary Materials}

Table S1: summary of concentrations of soil heavy metals collected from typical coal mining cities and nonmining cities in recent years $(\mathrm{mg} / \mathrm{kg})$. Table S2: correlation coefficients between different heavy metals. (Supplementary Materials)

\section{References}

[1] T. M. Schnorr, K. Steenland, M. J. Thun, and R. A. Rinsky, "Mortality in a cohort of antimony smelter workers," American Journal of Industrial Medicine, vol. 27, no. 5, pp. 759-770, 1995.

[2] D. Mergler, H. A. Anderson, L. H. M. Chan et al., "Methylmercury exposure and health effects in humans: a worldwide concern," AMBIO: A Journal of the Human Environment, vol. 36, no. 1, pp. 3-11, 2007.

[3] Y. S. Hedberg, B. Erfani, M. Matura, and C. Lidén, "Chromium(III) release from chromium-tanned leather elicits allergic contact dermatitis: a use test study," Contact Dermatitis, vol. 78, no. 5, pp. 307-314, 2018.

[4] M. Wang, R. Liu, W. Chen, C. Peng, and B. Markert, "Effects of urbanization on heavy metal accumulation in surface soils, Beijing," Journal of Environmental Sciences, vol. 64, pp. 328-334, 2018.

[5] G. Wang, S. Zhang, L. Xiao et al., "Heavy metals in soils from a typical industrial area in Sichuan, China: spatial distribution, source identification, and ecological risk assessment," Environmental Science and Pollution Research, vol. 24, no. 20, pp. 16618-16630, 2017.

[6] R. W. Feng, C. Y. Wei, S. X. Tu, F. C. Wu, and L. S. Yang, "Antimony accumulation and antioxidative responses in four fern plants," Plant and Soil, vol. 317, no. 1-2, pp. 93-101, 2009.

[7] E. Wcislo, J. Bronder, A. Bubak, E. Rodriguez-Valdes, and J. L. R. Gallego, "Human health risk assessment in restoring safe and productive use of abandoned contaminated sites," Environment International, vol. 94, pp. 436-448, 2016.

[8] W. Han, G. Gao, J. Geng, Y. Li, and Y. Wang, "Ecological and health risks assessment and spatial distribution of residual heavy metals in the soil of an e-waste circular economy park in Tianjin, China," Chemosphere, vol. 197, pp. 325-335, 2018. 
[9] J. Liu, J. Liang, X. Yuan et al., “An integrated model for assessing heavy metal exposure risk to migratory birds in wetland ecosystem: a case study in Dongting Lake Wetland, China," Chemosphere, vol. 135, pp. 14-19, 2015.

[10] S.-X. Quan, B. Yan, F. Yang, N. Li, X.-M. Xiao, and J.-M. Fu, "Spatial distribution of heavy metal contamination in soils near a primitive e-waste recycling site," Environmental Science and Pollution Research, vol. 22, no. 2, pp. 1290-1298, 2015.

[11] M. Romic and D. Romic, "Heavy metals distribution in agricultural topsoils in urban area," Environmental Geology, vol. 43, no. 7, pp. 795-805, 2003.

[12] Y. Wang, X. Duan, and L. Wang, "Spatial distribution and source analysis of heavy metals in soils influenced by industrial enterprise distribution: case study in Jiangsu province," Science of the Total Environment, vol. 710, Article ID 134953, 2020.

[13] L. Ma, Z. Yang, L. Li, and L. Wang, "Source identification and risk assessment of heavy metal contaminations in urban soils of Changsha, a mine-impacted city in Southern China," Environmental Science and Pollution Research, vol. 23, no. 17, pp. 17058-17066, 2016.

[14] J. Liang, C. Feng, G. Zeng et al., "Spatial distribution and source identification of heavy metals in surface soils in a typical coal mine city, Lianyuan, China," Environmental Pollution, vol. 225, pp. 681-690, 2017.

[15] X. Li, H. Yang, C. Zhang et al., "Spatial distribution and transport characteristics of heavy metals around an antimony mine area in central China," Chemosphere, vol. 170, pp. 17-24, 2017.

[16] S. K. Reza, U. Baruah, S. K. Singh, and T. H. Das, "Geostatistical and multivariate analysis of soil heavy metal contamination near coal mining area, northeastern India," Environmental Earth Sciences, vol. 73, no. 9, pp. 5425-5433, 2015.

[17] W. Hu, H. Wang, L. Dong et al., "Source identification of heavy metals in peri-urban agricultural soils of southeast China: an integrated approach," Environmental Pollution, vol. 237, pp. 650-661, 2018.

[18] J. Tang, M. He, Q. Luo, M. Adeel, and F. Jiao, "Heavy metals in agricultural soils from a typical mining city in China: spatial distribution, source apportionment, and health risk assessment," Polish Journal of Environmental Studies, vol. 29, no. 2, pp. 1379-1390, 2020.

[19] Y. Kang, G. Liu, C.-L. Chou, M. H. Wong, L. Zheng, and R. Ding, "Arsenic in Chinese coals: distribution, modes of occurrence, and environmental effects," Science of the Total Environment, vol. 412-413, pp. 1-13, 2011.

[20] S. Dai, R. Zeng, and Y. Sun, "Enrichment of arsenic, antimony, mercury, and thallium in a late permian anthracite from Xingren, Guizhou, southwest China," International Journal of Coal Geology, vol. 66, no. 3, pp. 217-226, 2006.

[21] S. F. Dai, D. Ren, Y. G. Tang, M. Yue, and L. M. Hao, "Concentration and distribution of elements in late permian coals from western Guizhou province, China," International Journal of Coal Geology, vol. 61, no. 1-2, pp. 119-137, 2005.

[22] L. Sun, D. Guo, K. Liu et al., "Levels, sources, and spatial distribution of heavy metals in soils from a typical coal industrial city of Tangshan, China," Catena, vol. 175, pp. 101109, 2019.

[23] L. Hua, X. Yang, Y. Liu, X. Tan, and Y. Yang, "Spatial distributions, pollution assessment, and qualified source apportionment of soil heavy metals in a typical mineral mining city in China," Sustainability, vol. 10, no. 9, p. 3115, 2018.
[24] L.-M. Cai, Q.-S. Wang, H.-H. Wen, J. Luo, and S. Wang, "Heavy metals in agricultural soils from a typical township in Guangdong province, China: occurrences and spatial distribution," Ecotoxicology and Environmental Safety, vol. 168, pp. 184-191, 2019.

[25] S. Xie, F. Yang, H. Feng, C. Wei, and F. Wu, "Assessment of potential heavy metal contamination in the peri-urban agricultural soils of 31 provincial capital cities in China," Environmental Management, vol. 64, no. 3, pp. 366-380, 2019.

[26] Z. Bian, X. Miao, S. Lei, S.-e. Chen, W. Wang, and S. Struthers, "The challenges of reusing mining and mineral-processing wastes," Science, vol. 337, no. 6095, pp. 702-703, 2012.

[27] X. Liu, J. Wu, and J. Xu, "Characterizing the risk assessment of heavy metals and sampling uncertainty analysis in paddy field by geostatistics and GIS," Environmental Pollution, vol. 141, no. 2, pp. 257-264, 2006.

[28] D. Hou, D. O'Connor, P. Nathanail, L. Tian, and Y. Ma, "Integrated GIS and multivariate statistical analysis for regional scale assessment of heavy metal soil contamination: a critical review," Environmental Pollution, vol. 231, pp. 11881200, 2017.

[29] H. Chen, Y. Teng, S. Lu, Y. Wang, and J. Wang, "Contamination features and health risk of soil heavy metals in China," Science of the Total Environment, vol. 512-513, pp. 143-153, 2015.

[30] W. Ben Achiba, N. Gabteni, A. Lakhdar et al., "Effects of 5year application of municipal solid waste compost on the distribution and mobility of heavy metals in a Tunisian calcareous soil," Agriculture, Ecosystems \& Environment, vol. 130, no. 3-4, pp. 156-163, 2009.

[31] R. Webster and M. A. Oliver, Geostatistics for Environmental Scientists, Wiley, Chichester, UK, 2nd edition, 2011.

[32] D. G. Krige, "A atatistical approach to some basic mine valuation problems on the Witwatersrand," Journal of the Chemical, Metallurgical and Mining Society of South Africa, vol. 52, pp. 119-139, 1951.

[33] L. Mabit and C. Bernard, "Assessment of spatial distribution of fallout radionuclides through geostatistics concept," Journal of Environmental Radioactivity, vol. 97, no. 2-3, pp. 206-219, 2007.

[34] P. Paatero and U. Tapper, "Positive matrix factorization: a non-negative factor model with optimal utilization of error estimates of data values," Environmetrics, vol. 5, no. 2, pp. 111-126, 1994.

[35] CNEMC, Background Values of Soil Elements in China, China Environmental Science Press, Beijing, China, 1990, in Chinese.

[36] J. Zou, X. Liu, W. Dai, and Y. Luan, "Pollution assessment of heavy metal accumulation in the farmland soils of Beijing's suburbs," Environmental Science and Pollution Research, vol. 25, no. 27, pp. 27483-27492, 2018.

[37] D. S. Manta, M. Angelone, A. Bellanca, R. Neri, and M. Sprovieri, "Heavy metals in urban soils: a case study from the city of Palermo (Sicily), Italy," Science of the Total Environment, vol. 300, no. 1-3, pp. 229-243, 2002.

[38] R. K. Sharma, M. Agrawal, and F. M. Marshall, "Atmospheric deposition of heavy metals $(\mathrm{Cu}, \mathrm{Zn}, \mathrm{Cd}$ and $\mathrm{Pb})$ in Varanasi City, India," Environmental Monitoring and Assessment, vol. 142, no. 1-3, pp. 269-278, 2008.

[39] K. B. Githaiga, S. M. Njuguna, V. A. Makokha et al., "Assessment of $\mathrm{Cu}, \mathrm{Zn}, \mathrm{Mn}$, and Fe enrichment in Mt. Kenya soils: evidence for atmospheric deposition and contamination," Environmental Monitoring and Assessment, vol. 192, no. 3, p. 167, 2020. 
[40] S. Charlesworth, M. Everett, R. McCarthy, A. Ordóñez, and E. de Miguel, "A comparative study of heavy metal concentration and distribution in deposited street dusts in a large and a small urban area: Birmingham and Coventry, West Midlands, UK," Environment International, vol. 29, no. 5, pp. 563-573, 2003.

[41] J. Liang, J. Liu, X. Yuan et al., "Facile synthesis of aluminadecorated multi-walled carbon nanotubes for simultaneous adsorption of cadmium ion and trichloroethylene," Chemical Engineering Journal, vol. 273, pp. 101-110, 2015.

[42] X. Xiao, J. Zhang, H. Wang et al., "Distribution and health risk assessment of potentially toxic elements in soils around coal industrial areas: a global meta-analysis," Science of the Total Environment, vol. 713, Article ID 135292, 2020.

[43] Y. Liu, S. Lei, and X. Chen, "Assessment of heavy metal pollution and human health risk in urban soils of a coal mining city in east China," Human and Ecological Risk Assessment, vol. 22, no. 6, pp. 1359-1374, 2016.

[44] X. Xu, J. Qian, E. Xie, X. Shi, and Y. Zhao, "Spatio-temporal change and pollution risk of agricultural soil cadmium in a rapidly industrializing area in the Yangtze Delta region of China," International Journal of Environmental Research and Public Health, vol. 15, no. 12, p. 2743, 2018.

[45] P. Pavlovic, M. Mitrovic, D. Dorclevic et al., "Assessment of the contamination of riparian soil and vegetation by trace metals-a Danube river case study," Science of the Total Environment, vol. 540, pp. 396-409, 2016.

[46] J. Lv, Y. Liu, Z. Zhang, and J. Dai, "Factorial kriging and stepwise regression approach to identify environmental factors influencing spatial multi-scale variability of heavy metals in soils," Journal of Hazardous Materials, vol. 261, pp. 387397, 2013.

[47] G. J. Liu, L. G. Zheng, Y. Zhang et al., "Distribution and mode of occurrence of as, $\mathrm{Hg}$ and Se and sulfur in coal seam 3 of the Shanxi formation, Yanzhou coalfield, China," International Journal of Coal Geology, vol. 71, no. 2-3, pp. 371-385, 2007.

[48] L. Xu, W. Luo, Y. Lu et al., "Status and fuzzy comprehensive assessment of metals and arsenic contamination in farmland soils along the Yanghe river, China," Chemistry and Ecology, vol. 27, no. 5, pp. 415-426, 2011.

[49] H. C. Cao, J. D. Wang, and X. L. Zhang, "Spatial distribution of $\mathrm{Cd}, \mathrm{Pb}$, as contents in the farmland black soil in Jilin province," Environmental Science, vol. 27, no. 10, pp. 21172122, 2006, in Chinese.

[50] H. G. Mikkonen, R. Dasika, J. A. Drake, C. J. Wallis, B. O. Clarke, and S. M. Reichman, "Evaluation of environmental and anthropogenic influences on ambient background metal and metalloid concentrations in soil," Science of the Total Environment, vol. 624, pp. 599-610, 2018.

[51] Y. Li, Y.-b. Wang, X. Gou, Y.-b. Su, and G. Wang, "Risk assessment of heavy metals in soils and vegetables around non-ferrous metals mining and smelting sites, Baiyin, China," Journal of Environmental Sciences, vol. 18, no. 6, pp. 11241134, 2006.

[52] T. Berg, E. Fjeld, and E. Steinnes, "Atmospheric mercury in Norway: contributions from different sources," Science of the Total Environment, vol. 368, no. 1, pp. 3-9, 2006.

[53] C. Li, Z. Nie, S. Cui, X. Gong, Z. Wang, and X. Meng, "The life cycle inventory study of cement manufacture in China," Journal of Cleaner Production, vol. 72, pp. 204-211, 2014.

[54] W.-Y. Li, L. Zhong, J. Feng, and K.-C. Xie, "Release behavior of $\mathrm{As}, \mathrm{Hg}, \mathrm{Pb}$, and $\mathrm{Cd}$ during coal gasification," Energy Sources, Part A: Recovery, Utilization, and Environmental Effects, vol. 32, no. 9, pp. 818-825, 2010.
[55] W. Q. Lin, Q. Sang, T. Yu, and M. F. Ma, "Restructing industry category and distribution across administrative areas based on environmental constraint-a case study of Wuhai and its surrounding regions, inner Mongolia autonomous region, China," Advanced Materials Research, vol. 524-527, pp. 3283-3289, 2012.

[56] L. Wang, S. Gao, X. Yin, X. Yu, and L. Luan, "Arsenic accumulation, distribution and source analysis of rice in a typical growing area in north China," Ecotoxicology and Environmental Safety, vol. 167, pp. 429-434, 2019.

[57] A. A. Meharg and M. M. Rahman, "Arsenic contamination of Bangladesh paddy field soils: implications for rice contribution to arsenic consumption," Environmental Science \& Technology, vol. 37, no. 2, pp. 229-234, 2003.

[58] M. A. Rahman, H. Hasegawa, M. M. Rahman, M. A. M. Miah, and A. Tasmin, "Straighthead disease of rice (Oryza sativa L.) induced by arsenic toxicity," Environmental and Experimental Botany, vol. 62, no. 1, pp. 54-59, 2008.

[59] Y. Li, F. Ye, A. Wang et al., "Chronic arsenic poisoning probably caused by arsenic-based pesticides: findings from an investigation study of a household," International Journal of Environmental Research and Public Health, vol. 13, no. 1, p. 133, 2016.

[60] T. Punshon, B. P. Jackson, A. A. Meharg, T. Warczack, K. Scheckel, and M. L. Guerinot, "Understanding arsenic dynamics in agronomic systems to predict and prevent uptake by crop plants," Science of the Total Environment, vol. 581-582, pp. 209-220, 2017.

[61] J. Zhou, K. Feng, Y. Li, and Y. Zhou, "Factorial kriging analysis and sources of heavy metals in soils of different landuse types in the Yangtze river delta of eastern China," Environmental Science and Pollution Research, vol. 23, no. 15, pp. 14957-14967, 2016.

[62] T. B. Chen, J. W. C. Wong, H. Y. Zhou, and M. H. Wong, "Assessment of trace metal distribution and contamination in surface soils of Hong Kong," Environmental Pollution, vol. 96, no. 1, pp. 61-68, 1997.

[63] X. Bi, X. Feng, Y. Yang et al., "Environmental contamination of heavy metals from zinc smelting areas in Hezhang county, western Guizhou, China," Environment International, vol. 32, no. 7, pp. 883-890, 2006.

[64] L. Jiang, J. Liang, X. Yuan et al., "Co-pelletization of sewage sludge and biomass: the density and hardness of pellet," Bioresource Technology, vol. 166, pp. 435-443, 2014.

[65] Y. Gao, H. Liu, and G. Liu, "The spatial distribution and accumulation characteristics of heavy metals in steppe soils around three mining areas in Xilinhot in inner Mongolia, China," Environmental Science and Pollution Research, vol. 24, no. 32, pp. 25416-25430, 2017. 